\title{
A Importância do Marketing Digital na Divulgação do Calendário de Eventos do Município de Santa Vitória Do Palmar/RS sob a Ótica da Comunidade
}

\author{
Francieli Boaria ${ }^{a}$ \\ Lidiane Caldeira de Souzab
}

\begin{abstract}
Resumo
O calendário de eventos é uma ferramenta muito utilizada pelas instituições público e privada com o intuito de divulgar e promover eventos. Com o desenvolvimento da tecnologia, sua forma online contribuiu imensuravelmente para a ampliação e alcance do público-alvo, pois a comunicação por meio da internet faz com que as notícias se disseminem em tempo real, sobretudo a partir da utilização das mídias sociais. Neste sentido, o foco deste estudo é verificar a importância e real necessidade de um calendário de eventos online para a comunidade do município de Santa Vitória do Palmar/RS, situado no extremo sul do país. A pesquisa realizada é do tipo exploratória de caráter descritiva, sua abordagem é quanti-qualitativa, e a coleta de dados foi realizada por meio de um questionário semiestruturado. Como resultados, constatou-se que um calendário de eventos online seria muito proveitoso para a comunidade, a qual muitas vezes desconhece a ocorrência proeminente de um evento, bem como para encontrar de forma mais ágil e confiável informações sobre a programação anual. Apurou-se também a ineficiência dos meios de comunicação em determinados locais do município, necessitando desta forma que a informação sobre o calendário de eventos seja também divulgada de forma impressa.
\end{abstract}

Palavras-chave: Eventos; Calendário de Eventos; Marketing Digital.

\begin{abstract}
The Importance of Digital Marketing in the Disclosure of the Calendar of Events in Santa Vitória do Palmar/RS City under the View of the Community TThe calendar of events is a tool widely used by public and private institutions in order to promote events. With the development of technology, its online form has contributed immeasurably to the expansion and reach of the target audience, since communication through the internet causes the news to be disseminated in real time, especially from the use of social media. In this sense, the focus of this study is to verify the importance and real need of an online event calendar for the community of the municipality of Santa Vitória do Palmar / RS, located in the extreme south of the country. The research carried out is of an exploratory type with a descriptive character, its approach is quanti-qualitative, and the data collection was performed through a semi-structured questionnaire. As a result, it was found that an online event calendar would be very beneficial to the community, which is often unaware of the prominent occurrence of an event, as well as to find information about the annual programming in a more agile and reliable way. The
\end{abstract}

a. Mestre em Turismo e Hotelaria pela Univali, Balneário Camboriú, SC, Brasil. Docente do curso de tecnologia em eventos da Universidade Federal do Rio Grande - FURG, Santa Vitória do Palmar, Rio Grande do Sul, Brasil. E-mail: franboaria@gmail.com.

b. Tecnóloga em Eventos pela Universidade Federal do Rio Grande - FURG, Santa Vitória do Palmar, Rio Grande do Sul, Brasil. E-mail: lidiane.souza2014@hotmail.com 
inefficiency of the means of communication in certain places of the municipality was also verified, thus requiring information on the calendar of events to be also disseminated in printed form.

Keywords: Events; Calendar of Events; Digital Marketing.

\section{Resumen}

La Importancia del Marketing Digital en la Divulgación del Calendario de Eventos en la Municipalidad de Santa Vitória do Palmar/RS bajo la Óptica de la Comunidad

El calendario de eventos es una herramienta ampliamente utilizada por las instituciones públicas y privadas con el fin de difundir y promover eventos. Con el desarrollo de la tecnología, su pedido online ha contribuido enormemente a ampliar y llegar al público objetivo, ya que la comunicación a través de internet hace que las noticias de la difusión en tiempo real, sobre todo por el uso de las medias sociales. En este sentido, el objetivo de este estudio es evaluar la importancia y la necesidad real de un calendario online de eventos de la comunidad en el municipio de Santa Vitória do Palmar/RS, que se encuentra en el extremo sur del país. La investigación es de carácter descriptivo exploratorio, su enfoque es cuantitativo y cualitativo, y la recogida de datos se realizó mediante un cuestionario semi-estructurado. Como resultado, se encontró que un calendario de eventos en línea sería muy beneficioso para la comunidad, que a menudo se pierde la ocurrencia de un evento importante, así como para encontrar una información más ágil y fiable en el calendario anual. Además, se averiguó la ineficacia de los medios de comunicación en ciertos lugares de la ciudad, por lo que requiere que la información sobre el calendario de eventos también se difunda en la forma impresa.

Palabras clave: Eventos; Calendario de Eventos; Marketing Digital.

\section{INTRODUÇÃo}

Em toda a história da humanidade sempre existiram eventos como uma forma de divertir e educar o povo, sendo que a cada dia os eventos se aprimoram em todas as áreas. Dentre inúmeras definições dos eventos, Britto e Fontes (2002, p. 20) o conceituam como "a soma de esforços e ações planejadas com o objetivo de alcançar resultados definidos junto ao seu público-alvo".

De acordo com o ll Dimensionamento Econômico da Indústria de Eventos no Brasil, o mercado de eventos cresceu nos últimos 12 anos em média, 14\% ao ano, acrescentando a participação no PIB do país de 3,1\% em 2001, para 4,32\%, no ano de 2013. No sentido da relevância do setor de eventos em relação a geração de emprego, renda e impostos, os números de geradores de empregos passaram de 7,5 milhões, sendo que a renda foi estimada de $\mathrm{R} \$ 209,2$ bilhões e os impostos foram mais de R $\$ 48$ bilhões (ABEOC; SEBRAE, 2013).

A localização para a realização dos eventos é de grande importância para a população autóctone, pois traz divertimento, educação, sociabilização, gera emprego, entre outros aspectos quando é de fácil acesso. Já o lazer faz parte dos direitos do ser humano, então fica claro a necessidade de distrações e entretenimentos que ajudem as pessoas a relaxarem na rotina diária estressante. Para os turistas, os eventos também têm uma importância significativa, pois quando se viaja para descansar, procura-se por diversão e entretenimento, e uma cidade com maior 
diversidade de eventos se torna mais atraente. Desta maneira, todos saem ganhando: o município com impostos, a população local pelo entretenimento e por conhecer novas pessoas e culturas, e os turistas por terem um descanso e divertimento.

Para o setor de eventos, o calendário é definido como uma publicação produzida por instituições públicas e/ou privadas com a finalidade de somar dados ligados a eventos, tais como data de realização, localidade e especialidade, planejando uma organização para evitar os conflitos de eventos (Castelli, 2006). A existência de um calendário de eventos auxilia muito na questão de não ocorrer à sobreposição de eventos que acaba prejudicando os organizadores por perderem o público, pois dificilmente conseguiriam atingir suas metas com dois eventos ocorrendo ao mesmo tempo, no mesmo município. Ter um calendário de eventos atualizado, onde figurem todos os dados necessários para as pessoas conseguirem se organizar com antecedência, é algo que traz tranquilidade e credibilidade ao evento, pois é possível uma melhor organização e alcançar um público bem maior através da correta e antecipada informação.

0 marketing digital tem uma grande influência no setor de eventos, pois facilita a aproximação do usuário à informação utilizando-se da internet. É através dele que a divulgação de um evento ocorre de maneira muito rápida facilitando tanto para o promotor de eventos quanto para quem deseja se informar e participar. Segundo Chleba (1999), o marketing digital tem sete forças que devem ser analisadas na hora de colocá-lo em prática, que são: interatividade, personalização, globalização, integração, aproximação, convergência e democratização da informação.

Inserido no marketing digital está a comunicação boca a boca online, que é extremamente eficiente, considerada das maiores formas de informação que existe, principalmente em municípios pequenos onde as pessoas se comunicam e ficam sabendo dos acontecimentos através dos parentes e amigos. Quando esta informação acontece virtualmente pelas mídias sociais, toda a rede de contatos tem acesso às informações, não se restringindo apenas às pessoas mais próximas, do cotidiano.

Esta pesquisa foi realizada no município de Santa Vitória do Palmar, que está localizado no sul do Rio Grande do Sul e conta com uma área de 5.244,353 $\mathrm{Km}^{2}$. Segundo o Instituto Brasileiro de Geografia e Estatística (IBGE), em 2010 possuía 30.990 habitantes e a população estimada de 2015 foi de 31.436 habitantes. Santa Vitória do Palmar possui duas praias: Praia Hermenegildo e a Praia da Barra do Chuí, a segunda localizada no extremo sul do território onde faz fronteira com o Uruguai. Possui ainda a Estação Ecológica do Taim e, unido ao município do Chuí, existe o maior complexo para geração energia eólica da América Latina que é o Complexo Eólico Campo Neutral, Parque Eólico Geribatu do Hermenegildo e do Chuí. A cidade é banhada por duas grandes lagoas, a Lagoa Mirim e a Lagoa Mangueira.

Na pesquisa sobre o calendário de eventos da prefeitura municipal de Santa Vitória do Palmar, detectou-se que ele não existe. Assim, tem-se como problema de pesquisa a necessidade da criação de um calendário de eventos online que possa atingir o maior número de pessoas. A fim de verificar a imprescindibilidade de se ter um calendário de eventos para a comunidade vitoriense, realizou-se 
uma pesquisa de campo no período de abril a junho de 2016 com os moradores de quatro diferentes regiões do município.

Destacar que no ano de 2014 foi criado o curso de Tecnologia em Eventos no campus da Universidade Federal do Rio Grande, localizado no município, o qual já possui egressos. Este dado é relevante no tocante da profissionalização dos eventos que já são realizados anualmente, e no incentivo do surgimento de novos eventos.

\section{Calendário de Eventos: Origem e Conceitos}

O calendário, em sua palavra genérica, trata de um objeto eminentemente cultural, um campo privilegiado de encontros das culturas popular e erudita. Os calendários aparecem em miniaturas e em esculturas na idade média, tornando-se desejados pelos grandes senhores e ricos burgueses. Os chineses ofereciam calendários aos vassalos para lembrar-lhes o poder sobre o tempo e os tributos pagos (Le Goff, 1982).

O calendário vem desde os tempos mais antigos sempre ligado a crenças e observações astronômicas. No Antigo Testamento diz: "E disse Deus: Que haja luzes no firmamento do céu para distinguir o dia e a noite e que sejam como sinais para as estações, para os dias e para os anos..." [Gênese, I, 14], isso mostra uma clara divisão do tempo, como para a formação de um calendário, com a divisão de dias, semanas, meses e anos. Os astrônomos foram os principais responsáveis pelas alterações feitas nos calendários ao longo dos anos (Le Goff, 1982).

Conforme Le Goff (1982) explana sobre o histórico do calendário neste e nos próximos parágrafos, na China, o gosto das elites pelo instrumento do calendário era tão grande que passou a ser objeto de uma ciência autônoma, como é visto na grande enciclopédia do século XVIII, o T'u-Shu Chi-Ch'êng (Coleção de pinturas e de escritos).

Júlio César, em 46 a.C. fez reformarem o calendário romano, tendo sido influenciado por Sosígenes, e a $1^{\text {o }}$ de janeiro do ano 45 a.C. começou a vigorar o novo calendário dito juliano que representou uma reforma radical no calendário romano tradicional, o qual foi dado o nome de sexto no início de março, por isso foi chamado de bis-sexto. Com efeito, o mês de fevereiro era um mês nefasto consagrado aos deuses infernais, com duração de vinte e oito dias. Ainda em Roma, tem-se que o poder religioso e político que eram intimamente interligados, com isso atribui-se o primeiro calendário a Numa Pompílio que era o fundador dos ritos e das instituições religiosas, e também que o controle do calendário se fazia necessário às autoridades religiosas para controlar a vida religiosa.

0 calendário ocupa um lugar muito importante nos primeiros séculos do cristianismo mostrando uma relevante importância para a Igreja Cristã. As especulações referentes ao calendário sagrado têm um importante papel no nascimento do sistema teológico e filosófico, como exemplo tem-se no alexandrino Basilides no começo do século II. Data essa que adquire uma importância essencial para o calendário romano: o domingo de Páscoa, dia em que Cristo ressuscitou. A igreja católica romana conseguiu impor uma reforma do calendário juliano em 1582, desta reforma surgiu o chamado calendário gregoriano, de Gregário XIII, o papa que atuou na reforma. 
As reformas juliana, gregoriana e chinesas provam que é possível uma reforma do calendário e que pode trazer grandes progressos. Porém, o calendário empenha os homens e toda a sociedade nos aspectos da sua vida e em sua história individual e coletiva. Para uma reforma do calendário ser bem-sucedida, deve-se antes respeitar a história (LE GOFF, 1982).

Para o setor de eventos, o calendário é um sistema de apuração e aglomeração de dias, o qual propende notar as necessidades civilizadas de uma cultura, ou seja, calendário de eventos é a afluência característica de eventos planejados (Denardin, 2013).

A escolha de eventos gera uma imagem para o turista, ao mesmo tempo em que estimula a receptividade dos destinos ampliando seus resultados na comunidade receptora. Entretanto, apenas com dados completos e corretos no calendário de eventos é que as pessoas apreciarão o destino, bem como cultivarão o interesse sobre o mesmo. É importante enfatizar que a elaboração prudente e caracterizada de um calendário de eventos desenvolve o número de visitantes, indica oportunidades para atividades econômicas, promove a geração de emprego e renda, divulga diretamente um local ou região, minimiza a sazonalidade turística e amplia a arrecadamento de impostos (Denardin, 2013).

O calendário de eventos possibilita ordenar as datas de realização dos eventos, para impedir possíveis sobreposições de alguns eventos afins. As sobreposições causam prejuízos aos próprios grupos envolvidos. Por exemplo, a execução do congresso nacional dos hoteleiros e dos agentes de viagem se concretizar na mesma data ou próximo dela dividem os participantes (Castelli, 2006).

Para Zitta (2013), o calendário deve ter a completa programação do evento, com datas, horários, local, atividades sociais, turísticas e de lazer, responsabilidades, contendo todas as informações necessárias para o público. 0 calendário deve apresentar o escopo do evento ao seu público-alvo, transmitindo informações necessárias como: o título do evento; as datas distribuídas de tempo e espaço; a abrangência; local de realização, a empresa que promoverá; seus patrocinadores, apoiadores e colaboradores; como outros aspectos importantes a serem seguidos.

Inúmeros calendários de eventos são publicados periodicamente tendo como finalidade básica a divulgação de uma gama de realizações. Os principais objetivos do calendário de eventos segundo Britto e Fontes (2002): providenciar um panorama total das programações, com tantas atrações naturais da cidade, tais como as festas folclóricas, dos eventos tecnicamente produzidos, ou seja, as feiras agropecuárias; coordenar as ações de divulgação e publicidade precisas a conquista das realizações; escolher os acontecimentos que tenham interesse pela demanda turística e a população; demonstrar informações necessárias, tanto para o usuário bem como aqueles que desejam, por meio desses calendários, estender e desenvolver a sua atividade comercial; probabilidade de levantamentos estatísticos das diversas concretizações, através do local, mês, características técnicas e entre outros. Já Martin (2007) destaca os principais objetivos com a elaboração do calendário de eventos, como: sua importância estratégica na diminuição da sazonalidade, através de um aumento do fluxo de visitantes ou público-alvo; ser um dos principais e competentes instrumentos de promoção e divulgação das programações de uma localidade; desenvolver e guiar as ações promocionais de publicidade e divulgação que serão precisas; ajuntar os aconte- 
cimentos de interesse para o público-alvo esperado; para um destino turístico, facilita a visualização dos alcances governamentais precisas para o recebimento dos eventos pelo município, como a concretização de obras públicas que atrapalhem ou evitem a execução do evento entre outros. Outro aspecto a ser constatado é a possibilidade de programar com antecedência obras de melhoramento da infraestrutura pública indispensável e melhoria na visualização dos eventos na ocasião, facilitando sua coordenação e impedindo a sobreposição de datas de eventos simultâneos que inviabilizem o destino turístico pela lotação da infraestrutura da localidade. Além disso, é fonte de consulta quando a demarcação da data de um imediato evento (Martin, 2007).

O calendário e a data escolhida são dois importantes tópicos quando se trata do tema eventos e sua captação. A primeira com o empenho de uma equipe, desde o planejamento até a divulgação. Já a segunda direcionada para o sucesso ou fracasso de um evento (Britto \& Fontes, 2002).

0 calendário de eventos, quando montado na internet, apresenta uma maior efetividade e intensidade para a publicação e divulgação turística. Comumente, fica disponível na página inicial de órgãos da administração pública municipal. Quando extremamente sofisticado e estruturado, é uma ferramenta usado pelos Convention \& Visitors Bureaux, bem como pelo governo (federal, estadual e municipal), a fim de gerar e publicar destinos turísticos.

Exemplifica-se no Quadro 1 um modelo ${ }^{1}$ utilizado no Iguassu Convention \& Visitors Bureau. Ressalta-se que a forma de utilização é adaptada conforme cada tipo de administração.

Quadro 1 - Calendário de Eventos ICVB 2016, dos meses de Junho e Julho.

\begin{tabular}{|c|c|c|c|c|c|c|c|}
\hline $\begin{array}{l}\text { Abrangên- } \\
\text { cia }\end{array}$ & $\begin{array}{l}\text { In- } \\
\text { ício }\end{array}$ & $\begin{array}{c}\text { Térmi- } \\
\text { no }\end{array}$ & Ano & Evento & Pax & Local & $\begin{array}{c}\text { Cap- } \\
\text { tado/ } \\
\text { Apoiado }\end{array}$ \\
\hline Nacional & $\begin{array}{l}\text { 01/ } \\
\text { Junho }\end{array}$ & $\begin{array}{l}\text { 03/ } \\
\text { Junho }\end{array}$ & 2016 & $\begin{array}{l}\text { 1a Feira e Conferên- } \\
\text { cia Internacional } \\
\text { de Soluções em } \\
\text { Conversão Térmica e } \\
\text { Biogás }\end{array}$ & 1.200 & $\begin{array}{l}\text { Rafain Palace } \\
\text { Hotel \& Con- } \\
\text { vention }\end{array}$ & Apoiado \\
\hline Regional & $\begin{array}{l}\text { 04/ } \\
\text { Junho }\end{array}$ & $\begin{array}{l}\text { 06/ } \\
\text { Junho }\end{array}$ & 2016 & $\begin{array}{l}\text { XI Congresso Sul } \\
\text { Brasileiro de Acu- } \\
\text { puntura }\end{array}$ & 200 & $\begin{array}{l}\text { Bourbon } \\
\text { Cataratas } \\
\text { Convention } \\
\text { \& SPA Resort }\end{array}$ & Captado \\
\hline Nacional & $\begin{array}{l}\text { 08/ } \\
\text { Junho }\end{array}$ & $\begin{array}{l}\text { 11/ } \\
\text { Junho }\end{array}$ & 2016 & $\begin{array}{l}\text { V Congresso Sul Bra- } \\
\text { sileiro de Medicina } \\
\text { de Família e Comu- } \\
\text { nidade VII Congres- } \\
\text { so do Cone Sul de } \\
\text { Medicina de Família }\end{array}$ & 700 & $\begin{array}{l}\text { Golden Park } \\
\text { Internacion- } \\
\text { al Foz }\end{array}$ & Captado \\
\hline
\end{tabular}

(continua...)

1. Modelo de apenas dois meses, extraído do site do Iguassu Covention \& Visitors Bureau. 
Quadro 1 - Continuação

\begin{tabular}{|c|c|c|c|c|c|c|c|}
\hline $\begin{array}{l}\text { Abrangên- } \\
\text { cia }\end{array}$ & $\begin{array}{l}\text { In- } \\
\text { ício }\end{array}$ & $\begin{array}{c}\text { Térmi- } \\
\text { no }\end{array}$ & Ano & Evento & Pax & Local & $\begin{array}{c}\text { Cap- } \\
\text { tado/ } \\
\text { Apoiado }\end{array}$ \\
\hline Nacional & $\begin{array}{l}\text { 15/ } \\
\text { Junho }\end{array}$ & $\begin{array}{l}\text { 17/ } \\
\text { Junho }\end{array}$ & 2016 & $\begin{array}{l}50^{\circ} \text { Congresso } \\
\text { Nacional da ABIPEM } \\
\text { (Associação Brasilei- } \\
\text { ra de Instituições de } \\
\text { Previdência Estadu- } \\
\text { ais e Municipais). }\end{array}$ & 1.000 & $\begin{array}{l}\text { Bourbon } \\
\text { Cataratas } \\
\text { Convention } \\
\text { \& SPA Resort }\end{array}$ & Captado \\
\hline Nacional & $\begin{array}{l}\text { 15/ } \\
\text { Junho }\end{array}$ & $\begin{array}{l}17 / \\
\text { Junho }\end{array}$ & 2016 & $\begin{array}{l}\text { Festival de Turismo } \\
\text { das Cataratas - Foz } \\
\text { do Iguaçu Travel } \\
\text { Market }\end{array}$ & 6.000 & $\begin{array}{l}\text { Rafain Palace } \\
\text { Hotel \& Con- } \\
\text { vention }\end{array}$ & Apoiado \\
\hline ICCA & $\begin{array}{l}\text { 19/ } \\
\text { Junho }\end{array}$ & $\begin{array}{l}\text { 23/ } \\
\text { Junho }\end{array}$ & 2016 & $\begin{array}{l}\text { 5th Internation- } \\
\text { al Conference on } \\
\text { Engineering Optimi- } \\
\text { zation }\end{array}$ & 250 & $\begin{array}{l}\text { Rafain Palace } \\
\text { Hotel \& Con- } \\
\text { vention }\end{array}$ & \\
\hline Regional & $\begin{array}{l}\text { 23/ } \\
\text { Junho }\end{array}$ & $\begin{array}{l}\text { 25/ } \\
\text { Junho }\end{array}$ & 2016 & $\begin{array}{l}\text { XX Jornada do Cone } \\
\text { Sul de Reumatologia }\end{array}$ & 3.000 & $\begin{array}{l}\text { Bourbon } \\
\text { Cataratas } \\
\text { Convention } \\
\text { \& SPA Resort }\end{array}$ & Apoiado \\
\hline ICCA & $\begin{array}{l}\text { 26/ } \\
\text { Junho }\end{array}$ & $\begin{array}{l}\text { 30/ } \\
\text { Junho }\end{array}$ & 2016 & $\begin{array}{l}\text { 8th Internation- } \\
\text { al Conference on } \\
\text { Bridge Maintenance, } \\
\text { Safety and Manage- } \\
\text { ment -IABMAS }\end{array}$ & 700 & $\begin{array}{l}\text { Bourbon } \\
\text { Cataratas } \\
\text { Convention } \\
\text { \& SPA Resort }\end{array}$ & $\begin{array}{l}\text { Captado/ } \\
\text { Apoiado }\end{array}$ \\
\hline ICCA & $\begin{array}{l}\text { 10/ } \\
\text { Julho }\end{array}$ & $\begin{array}{l}\text { 13/ } \\
\text { Julho }\end{array}$ & 2016 & $\begin{array}{l}21 \text { International } \\
\text { Chromosome Con- } \\
\text { ference - } 21 \text { ICC- }\end{array}$ & 500 & $\begin{array}{l}\text { Rafain Palace } \\
\text { Hotel \& Con- } \\
\text { vention }\end{array}$ & Apoiado \\
\hline $\begin{array}{l}\text { Internac- } \\
\text { ional }\end{array}$ & $\begin{array}{l}\text { 04/ } \\
\text { Julho }\end{array}$ & $\begin{array}{l}08 / \\
\text { Julho }\end{array}$ & 2016 & $\begin{array}{l}\text { 1st Joint Meeting } \\
\text { ISCE/ ALAEQ }\end{array}$ & 300 & $\begin{array}{l}\text { Recanto } \\
\text { Cataratas } \\
\text { - Thermas, } \\
\text { Resort e } \\
\text { Convention }\end{array}$ & Apoiado \\
\hline ICCA & $\begin{array}{l}\text { 04/ } \\
\text { Julho }\end{array}$ & $\begin{array}{l}09 / \\
\text { Julho }\end{array}$ & 2016 & $\begin{array}{l}\text { 32nd Annual Meet- } \\
\text { ing of the Interna- } \\
\text { tional Society of } \\
\text { Chemical Ecology } \\
\text {-ISCE- }\end{array}$ & 300 & $\begin{array}{l}\text { Recanto } \\
\text { Cataratas } \\
\text { - Thermas, } \\
\text { Resort e } \\
\text { Convention }\end{array}$ & Apoiado \\
\hline
\end{tabular}

Fonte: Iguassu Convention \& Visitors Bureau (2016).

O calendário de eventos é uma ferramenta de acréscimo e divulgação de uma empresa, local, região ou país. Ele compõe a descrição dos eventos, como costumes ou atrativos que serão projetados para ser efetivado em determinado local ou região, que cumpra o período de tempo. Sendo assim, o principal objetivo do calendário é divulgar os eventos para o público em geral ou para o determinado público específico, porém, depende do perfil de um evento ou tipo de evento a ser realizado (MARTIN, 2007).

Para a programação do calendário de eventos, Britto e Fontes (2002) explicam que devem ser levados em conta: o levantamento e a análise das necessidades 
do mercado; opção pela utilização do calendário de eventos; elaboração de um esboço do calendário; captação de eventos externos para o preenchimento do calendário; criação de eventos internos para a complementação do calendário; divulgação do calendário preparado; apoio e cooperação financeira ao núcleo na execução do calendário; apoio político e técnico do órgão representativo do turismo local à implantação do calendário de eventos (BRITTO; FONTES, 2002).

Martin (2007) complementa com alguns critérios de elaboração de um calendário, como: definição do público-alvo; área de abrangência; ordenação do conteúdo; viabilização econômica do calendário; distribuição; venda; circulação; apresentação e conteúdo. Além desses critérios, é necessário pensar nas diversas formas de ordenação do conteúdo que pode conter por: abrangência; cronologia; segmento de atividade econômica ou segmento professional; ordem alfabética; local de realização; área de interesse; tipologia.

Os calendários de fato possibilitam uma consulta de fácil acesso e rápida do evento que acontecerá em um determinado espaço ou local, por conter todas as informações necessárias sobre a realização do evento em uma única ferramenta de consulta. Também promovem a execução de dados estatísticas, em razão do seu público-alvo quanto para o trade turístico e o mercadológico, como por exemplo, total de eventos por conjuntos profissionais, períodos com o máximo índice de eventos, entre outros.

O calendário de eventos de um município ou região é necessário para a divulgação dos eventos, ter como referência, sendo uma consulta de caráter rápido e facilitador. De acordo com Martin (2007), os benefícios atribuídos para o município quanto ao uso do calendário de eventos, que é uma das principais ferramentas utilizadas pelos Convention \& Visitors Bureaux e governos, com sua abrangência municipais, estaduais e federais, são:

1. 1. Ampliação do número de visitantes: com o melhoramento da divulgação do destino, acrescenta-se os turistas e o consumo de bens e serviços no local;

2. 2. Criação de oportunidades: amplia as possibilidades de viagens e o movimento no trade turístico. Impulsiona o comércio local; manutenção e estímulo aos graus de emprego, tanto o setor de turístico quanto os demais setores de bens e serviços são estimulados, uma vez que o turismo alcança mais de 50 diferentes setores econômicos;

3. 3. Divulgação espontânea: é a divulgação que não é paga pelo benefício dela. Ou seja, envolve toda a notícia, difundida em qualquer mídia, que tem geração espontânea pela imprensa. Se o evento for de interesse da população ou do público-alvo, o calendário desperta atenção dessa mídia, que terá interesse em divulgá-lo gratuitamente; acréscimo da coleta de impostos: desenvolvendo-se o consumo, amplia-se os impostos coletados.

\section{Marketing Digital direcionado para os Eventos}

O marketing de eventos é diferente da propaganda, da promoção, da divulgação no ponto de venda ou das relações públicas, mas em geral incorpora elementos de todos esses instrumentos de comunicação (Crescitelli; Shimp, 2012). De acordo com Paiva e Neves "[...] o termo Turismo de Eventos tem sido empregado 
para descrever esta situação, dado ao desenvolvimento de marketing sistemático de eventos especiais como atrativos turísticos" (2008, p. 4).

Dentro do marketing clássico encontram-se as mídias tradicionais, tais como os jornais, rádios, TV, revistas, telefone e internet. A partir da evolução tecnológica, as opções de marketing se expandiram, citando algumas ferramentas como mídias e redes sociais, links patrocinados, e-commerce, mobile marketing, entre outros.

Torres (2010) define o marketing digital como um conjunto de métodos de publicidade e marketing usados na internet e para analisar uma nova maneira de se comportar dos usuários quando estão navegando na rede. São ações usadas na web para proporcionar um contato entre a empresa e o cliente.

Boaria (2013) comenta que a utilização do marketing digital é essencialmente lançar conteúdos em canais digitais como blogs, sites e mídias sociais (redes sociais como Facebook, Google+, Twitter, Linkedin, Slideshare, Instagram), que possuem o poder de veicular uma mensagem de maneira descentralizada aos amplos meios de comunicação de massa e propagar conteúdo ao mesmo tempo em que possibilitem alguma analogia com outras pessoas, tais como jogos, aplicativos e também da forma paga, através de banners, anúncios ou diversos conteúdos pagos publicado na internet.

Conforme explica Torres (2009), o smartphone é um sucesso inegável e tem se tornado uma plataforma móvel que possibilita a transmissão de mensagem de texto, denominados torpedos ou SMS. A vinda do iPhone, com a sua nova definição e tecnologias, apressou o ritmo de mercado devido a chegada dos smartphones, com todas as funcionalidades que compõe o computador. $\mathrm{O}$ aplicativo Whatsapp veio a melhorar ainda mais a comunicação, pois mesmo sem área para celulares, com o WIFI é possível à comunicação.

De acordo com Crescitelli e Shimp (2012), a comunicação conhecida como boca a boca (direta ou online) tem um resultado multiplicador de significativa importância. Esta comunicação é influenciada por um formador de opinião (pessoa colocada na rede social de família, amigos e conhecidos com um controle sobre as atitudes e comportamento de outros indivíduos). Os formadores de opinião exercitam diversas funções importantes: eles comunicam às outras pessoas sobre produtos, dão conselhos e restringem o risco a quem os ouve, ao comprar ou utilizar um produto e proporcionam também um feedback de caráter prático para aprovar ou apoiar decisões que os seguidores adotaram. Assim, um formador de opinião "é um informante, um persuasor e um confirmador" (p. 463).

Outro aspecto importante do marketing digital em relação à influência interpessoal online ou boca a boca online (em inglês electronic word of mouth ou e-WOM), quando a comunicação boca a boca se torna digital, a internet infere novas formas de pesquisa, interpretação de informações, e ativa para reconhecer a influência que um consumidor pode ter (Boaria; Anjos; Raye, 2014). Fotis, Buhalis e Rossides (2012) e Manap e Adzharudin (2013) corroboram quando afirmam que o e-WOM atrai turistas.

Cada destino turístico ou município precisa ter um calendário anual de eventos para ser compartilhado, assim tornando-se um "boca a boca online", pois é a fonte de informação que exprime fatos e costumes diferentes, transmitindo um conhecimento mais denso da valorização, a qual evidencia os atrativos. No calendário de eventos são notadas as programações dentro da cidade anualmente, que 
se caracteriza pela divulgação e publicação, promoção e comercialização desta localidade ou parte de seus encantos.

\section{Metodologia e Discussão dos Dados}

Este estudo caracteriza-se por uma pesquisa do tipo exploratória de caráter descritivo por se propor a identificar e verificar a importância de um calendário de eventos online para a comunidade do município de Santa Vitória do Palmar/ RS, abrangendo aspectos de sua caracterização e essencialidade do marketing digital na divulgação dos eventos. Para alcançar este objetivo, uma pesquisa de campo foi realizada na comunidade local no período de abril a junho de 2016, abrangendo quatro localidades conforme apresenta-se na Tabela 1, totalizando 67 entrevistados, representando a amostra da pesquisa.

Tabela 1 - Amostra da pesquisa

\begin{tabular}{|l|l|}
\multicolumn{1}{|c|}{ Localidade } & \multicolumn{1}{c|}{ Amostra } \\
\hline Praia do Hermenegildo & 11 \\
\hline Balneário Barra do Chuí & 9 \\
\hline Centro SVP & 26 \\
\hline Campanha (interior) & 21 \\
\hline
\end{tabular}

Fonte: Elaborado pelas autoras.

Nota: SVP: abreviatura de Santa Vitória do Palmar

Destaca-se que o universo de campanhas (ou fazendas) são 35, e 11 aceitaram participar da pesquisa, sendo elas: Alvorada, Espinilho, Índia Morta, Granja Geribatu, Granja Mangueira, Granja Mirim, Curi, Granja Darci Zanetti, Vila Anselmo, Vila Ipiranga, Josapar, onde atingiu-se 21 entrevistados na comunidade local.

A fim de apresentar as distâncias territoriais e diferentes características, as Figuras 1 e 2 são apresentadas. 
Figura 1 - Localização das Campanhas/Fazendas Santa Vitória do Palmar/RS que participaram da pesquisa

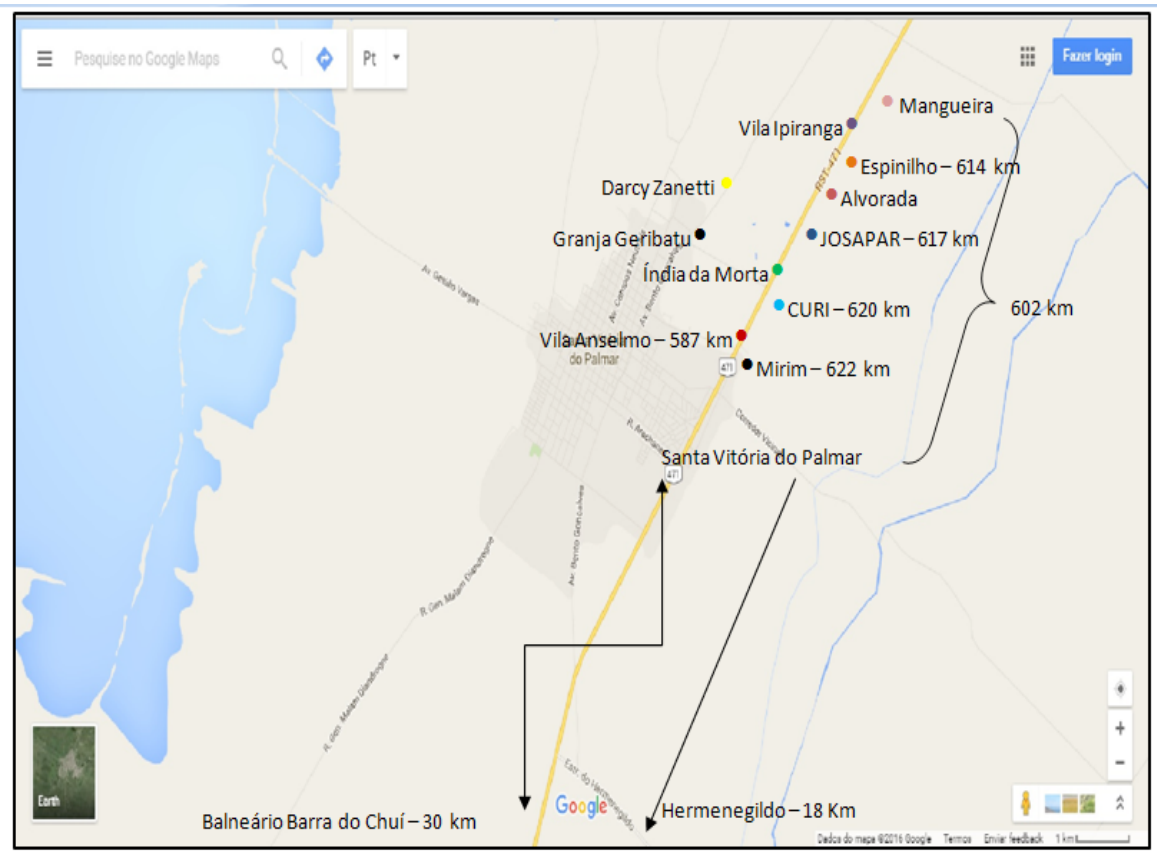

Fonte: Google Maps (2016).

Figura 2 - Localização Santa Vitória do Palmar/RS - Região Cento Urbano

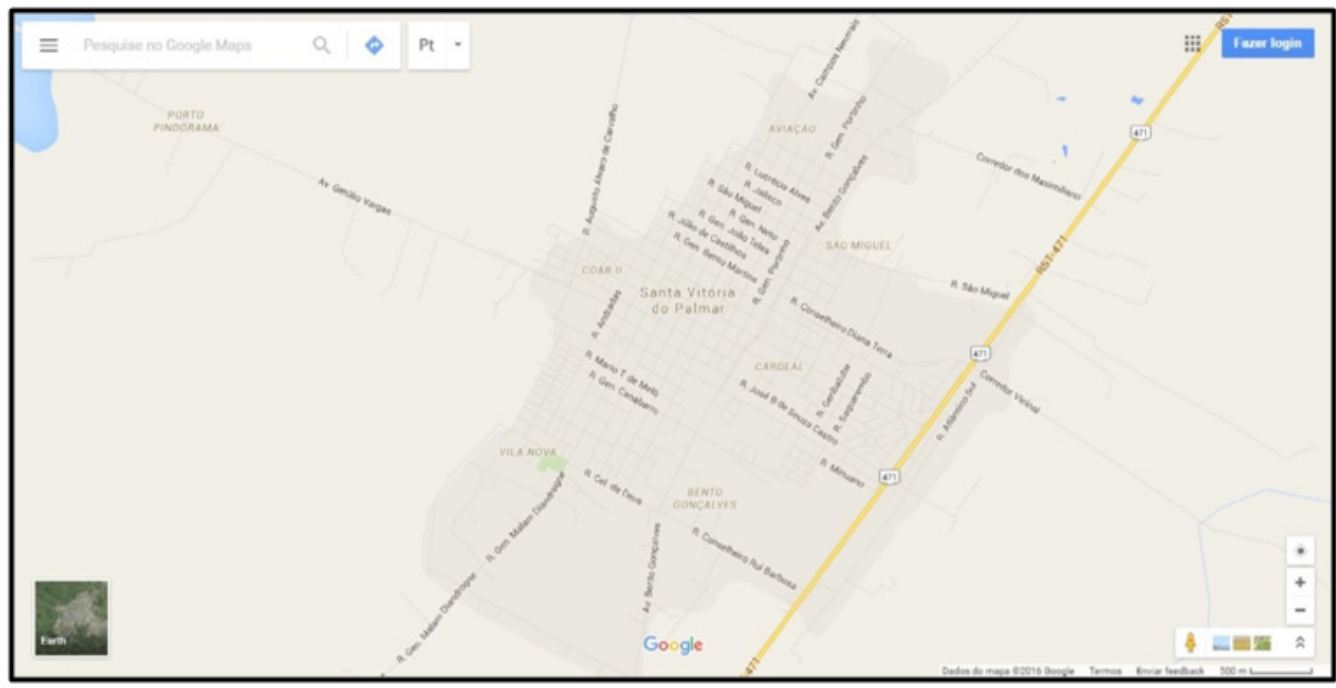

Fonte: Google Maps (2016).

Nas Figuras 1 e 2 é possível identificar que a distância do centro do município até a campanha ou campo mais distante participante da pesquisa possui 59,5 quilômetros; a Barra do Chuí, praia mais distante, está à 30,8 quilômetros do centro de SVP. Ressalta-se que neste estudo foram considerados estes quatro pontos geográficos a fim de melhor diagnosticar o perfil do público-alvo, além de identificar como as comunidades destes quatro locais recebem as informações sobre futuros eventos. 
Para uma melhor identificação e credibilidade dos questionários aplicados, realizou-se perguntas com questões pessoais, traçando os perfis dos respondentes conforme apresenta-se na Tabela 2.

Tabela 2 - Característica dos respondentes amostra da pesquisa.

\begin{tabular}{|c|c|c|}
\hline & $N=67$ & $\%$ \\
\hline \multicolumn{3}{|l|}{ Gênero } \\
\hline Feminino & 42 & 62,68 \\
\hline Masculino & 25 & 37,31 \\
\hline \multicolumn{3}{|l|}{ Faixa etária (anos) } \\
\hline 18 А 20 & 4 & 5,97 \\
\hline 20 А 29 & 16 & 23,88 \\
\hline 30 A 39 & 15 & 22,38 \\
\hline 40 А 49 & 15 & 22,38 \\
\hline Acima de 50 anos & 17 & 25,37 \\
\hline \multicolumn{3}{|l|}{ Grau de escolaridade } \\
\hline Ensino Fundamental Incompleto & 17 & 25,37 \\
\hline Ensino Médio Incompleto & 6 & 8,95 \\
\hline Ensino Médio Completo & 8 & 11,94 \\
\hline Ensino Técnico Profissionalizante & 1 & 1,49 \\
\hline Ensino Superior Incompleto & 17 & 25,37 \\
\hline Ensino Superior Completo & 8 & 11,94 \\
\hline Pós-graduação & 4 & 5,97 \\
\hline Ensino Fundamental Completo & 5 & 7,46 \\
\hline Analfabeto & 1 & 1,49 \\
\hline
\end{tabular}

Fonte: Elaborado pelas autoras.

Com relação ao gênero da amostra, apenas na campanha o gênero masculino se sobressaiu sobre o feminino. Já com relação à idade, nas regiões da praia do Hermenegildo, Barra do Chuí e campanha, os respondentes possuem mais de 40 anos (15 entrevistados), enquanto que no centro, a maior parte (10) possui entre 21 a 30 anos. No que tange ao grau de escolaridade, apenas no centro de SVP 14 respondentes possuem ensino superior incompleto; as demais regiões abrangem ensino fundamental completo e ensino médio incompleto.

Devido à importância da tecnologia da informação e comunicação (TICs) para a divulgação dos eventos e por este trabalho abordar este tema, diferentes questões foram elaboradas para verificar a disponibilidade e acesso da internet pela amostra da pesquisa, onde identificou-se que em algumas campanhas não há acesso à internet (não há torre de celular ou internet por rádio). No restante da amostra, todas as regiões têm acesso à internet.

A amostra foi consultada sobre os equipamentos para a utilização da internet, dentre eles, o computador de mesa, notebook e celular/smartphone, sobressain- 
do-se o smartphone na praia do Hermenegildo, Barra do Chuí e centro do município. Quando há acesso à internet, na campanha também se utiliza este equipamento, corroborando com Torres (2009), que menciona a importância deste equipamento na rotina das pessoas.

Além disso, esta pesquisa identificou que a mídia social mais utilizada é o facebook, ficando em segundo lugar o Whatsapp. Sendo assim, as redes sociais se tornam consideráveis ferramentas estratégicas para empresas de todos os tamanhos e de todos os setores da economia, dando oportunidade às vantagens. A cada dia, o novo cliente está mais ligado com o ambiente virtual e hábil a efetuar distintas atividades online, com inclusão das compras.

As ferramentas utilizadas para a divulgação dos eventos que ocorrem no município são de extrema importância para a captação do público-alvo. Neste item, os respondentes salientaram a importância de um calendário de eventos, conforme demonstra-se no Gráfico 1.

Gráfico 1 - Ferramentas de divulgação mais utilizadas

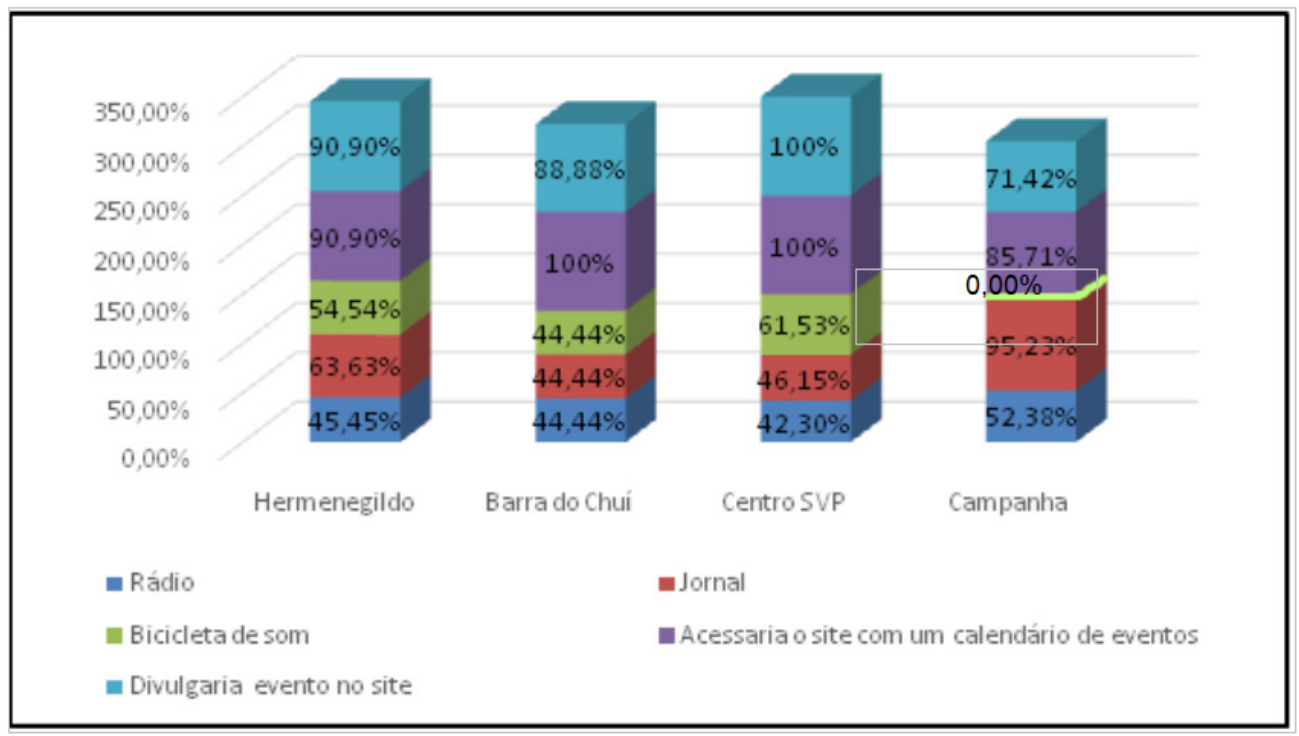

Fonte: Elaborado pelas autoras.

Diante dos resultados apresentados no Gráfico 1, ressalta-se que a maior parte respondeu que acessaria o site com calendário de eventos para informar-se sobre o planejamento dos eventos no município. Os entrevistados também responderam positivamente quanto à divulgação dos eventos neste site. É comum a utilização de uma bicicleta de som para a divulgação de eventos e empresas na cidade de SVP, porém, identifica-se nesta pesquisa que esta ferramenta de marketing não chega até as campanhas. Da amostra pesquisada, os habitantes da campanha são os que mais leem jornal.

Para obter sucesso em um evento, o público-alvo deve ser atingido por meio de sua divulgação. Assim, buscou-se verificar se a comunidade fica sabendo da 
realização dos eventos ou se já perdeu algum evento por falta de informação, conforme apresenta-se no Gráfico 2.

Gráfico 2 - Divulgação dos eventos

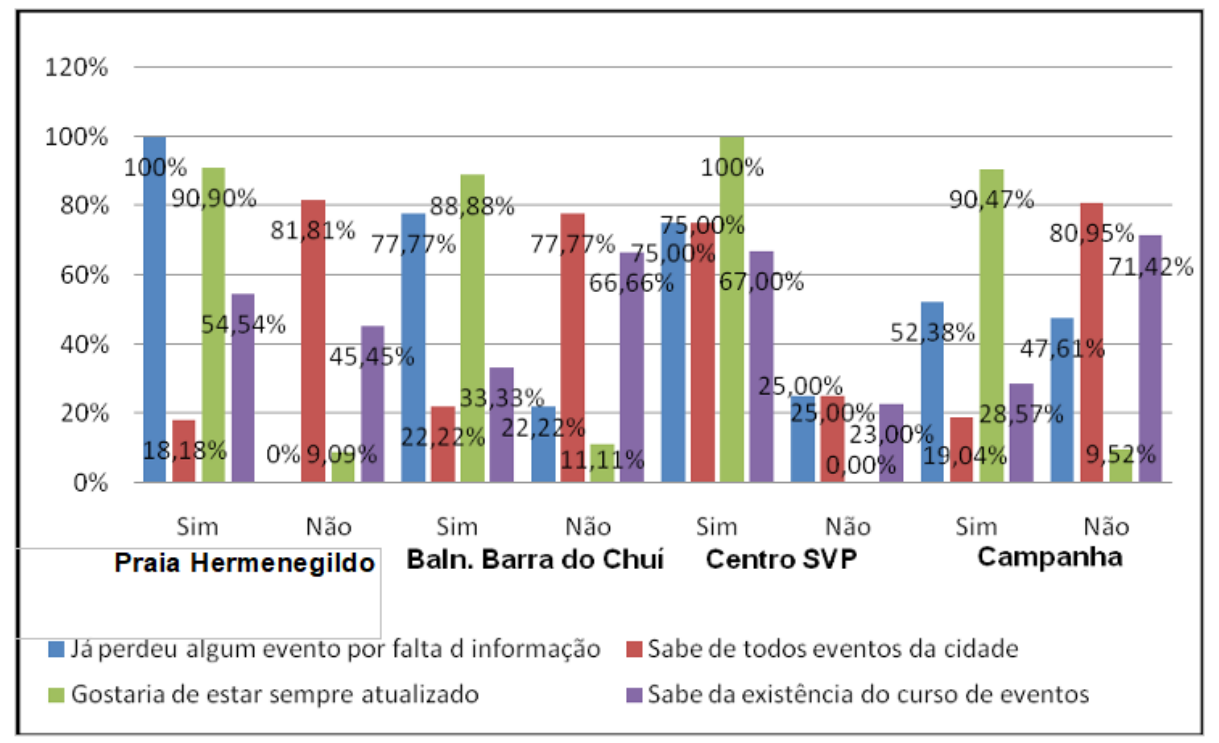

Fonte: Elaborado pelas autoras.

Destaca-se no Gráfico 2 que em todas as regiões muitos entrevistados afirmaram que já perderam algum evento por falta de informação/divulgação, sendo $100 \%$ na praia do Hermenegildo. Muitos participantes da pesquisa desconhecem a existência de um curso de eventos no município, que durante a aplicação da pesquisa fazia pouco mais de dois anos de sua existência.

Devido à necessidade de identificar a importância dos eventos para a comunidade, aplicou-se questões para identificar a participação em relação aos eventos, quando a informação chega até a comunidade. A Tabela 3 apresenta resultados de uma questão aberta do instrumento de pesquisa, à qual a comunidade mencionou se participa de algum evento.

Tabela 3 - Participação da comunidade em eventos

\begin{tabular}{|l|l|l|l|l|l|}
\hline & $\begin{array}{c}\text { Praia do Her- } \\
\text { menegildo }\end{array}$ & $\begin{array}{c}\text { Bal. Barra do } \\
\text { Chuí }\end{array}$ & Centro SVP & Campanha & TOTAL \\
\hline Eventos & $\mathrm{N}=11$ & $\mathrm{~N}=9$ & $\mathrm{~N}=26$ & $\mathrm{~N}=21$ & $\mathrm{~N}=67$ \\
\hline Festa de Iemanjá & 1 & 0 & 0 & 0 & 1 \\
\hline Carnaval & 1 & 0 & 3 & 3 & 7 \\
\hline $\begin{array}{l}\text { Festas sociais (ex.: } \\
\text { baile) }\end{array}$ & 2 & 2 & 3 & 3 & 10 \\
\hline Festas Escolares & 1 & 1 & & & 2 \\
\hline Festas de Clubes & 1 & 0 & 0 & 0 & 1 \\
\hline Músicas & 0 & 1 & 0 & 0 & 1 \\
\hline Teatro & 0 & 1 & 0 & 1 & 1 \\
\hline Rodeios & 0 & 1 & 2 & 2 & 3 \\
\hline
\end{tabular}

(continua...) 
Tabela 3 - Continuação

\begin{tabular}{|c|c|c|c|c|c|}
\hline & $\begin{array}{c}\text { Praia do Her- } \\
\text { menegildo }\end{array}$ & $\begin{array}{l}\text { Bal. Barra do } \\
\text { Chuí }\end{array}$ & Centro SVP & Campanha & TOTAL \\
\hline $\begin{array}{l}\text { Eventos de trabalho } \\
\text { e da escola }\end{array}$ & 0 & 1 & 0 & 0 & 1 \\
\hline Shows & 0 & 1 & 2 & 2 & 5 \\
\hline Seminários & 0 & 0 & 1 & 1 & 2 \\
\hline Congressos & 0 & 0 & 1 & 1 & 2 \\
\hline Feiras & 0 & 0 & 1 & 1 & 2 \\
\hline Mais Bela Estudante & 0 & 0 & 1 & 1 & 2 \\
\hline $\begin{array}{l}\text { Eventos na } \\
\text { faculdade }\end{array}$ & 0 & 0 & 1 & 1 & 2 \\
\hline Chama Crioula & 0 & 0 & 1 & 1 & 2 \\
\hline 20 de Setembro & 0 & 0 & 0 & 0 & 0 \\
\hline Torneio & 0 & 0 & 1 & 1 & 2 \\
\hline Baile & 0 & 0 & 1 & 1 & 2 \\
\hline Expofeira & 0 & 0 & 1 & 1 & 2 \\
\hline Palestras & 0 & 0 & 1 & 1 & 2 \\
\hline Melhores do Ano & 0 & 0 & 3 & 3 & 6 \\
\hline Eventos Turísticos & 0 & 0 & 2 & 2 & 4 \\
\hline $\begin{array}{l}\text { Domingo Impera- } \\
\text { dores (baile) }\end{array}$ & 0 & 0 & 1 & 1 & 2 \\
\hline Eventos Científicos & 0 & 0 & 1 & 1 & 2 \\
\hline Sim (se participa) & 5 & 6 & 17 & 17 & 45 \\
\hline Não (se participa) & 6 & 3 & 9 & 9 & 27 \\
\hline
\end{tabular}

Destacam-se na Tabela 3 características culturais específicas da região, a citar: festa de Iemanjá, Rodeios, Mais Bela Estudante, Chama Crioula, Domingo Imperadores e Expofeira. Além disso, mais da metade da amostra afirmou que participa dos eventos de forma geral, enfatizando aqui a relevância de um calendário de eventos para o município.

Com o intuito de averiguar como a comunidade local tem conhecimento sobre os eventos que ocorrem no município, uma questão aberta procurou identificar os mais variados meios utilizados, conforme demonstra-se na Tabela 4.

Tabela 4 - Como fica sabendo dos eventos

\begin{tabular}{|l|l|l|l|l|l|}
\hline & $\begin{array}{c}\text { Praia do Herme- } \\
\text { negildo }\end{array}$ & $\begin{array}{c}\text { Bal. Barra do } \\
\text { Chuí }\end{array}$ & Centro SVP & Campanha & TOTAL \\
\hline Ferramentas & $\mathrm{N}=11$ & $\mathrm{~N}=9$ & $\mathrm{~N}=26$ & $\mathrm{~N}=21$ & $\mathrm{~N}=67$ \\
\hline Rádio & 3 & 3 & 7 & 7 & 20 \\
\hline Rede Social & 2 & 0 & 4 & 4 & 10 \\
\hline Boca a Boca & 4 & 3 & 17 & 17 & 41 \\
\hline Facebook & 1 & 2 & 5 & 5 & 13 \\
\hline Mídia & 1 & 0 & 0 & 0 & 1 \\
\hline
\end{tabular}

(continua...) 
Tabela 4 - Continuação

\begin{tabular}{|l|l|l|l|l|l|} 
& $\begin{array}{c}\text { Praia do Herme- } \\
\text { negildo }\end{array}$ & $\begin{array}{c}\text { Bal. Barra do } \\
\text { Chuí }\end{array}$ & Centro SVP & Campanha & TOTAL \\
\hline Internet & 1 & 0 & 7 & 7 & 15 \\
\hline $\begin{array}{l}\text { Depois que } \\
\text { acontece }\end{array}$ & 0 & 1 & 0 & 0 & 1 \\
\hline Não sabe & 0 & 1 & 1 & 1 & 3 \\
\hline Sites & 0 & 0 & 1 & 1 & 2 \\
\hline Tv & 0 & 0 & 2 & 2 & 4 \\
\hline Bicicleta & 0 & 0 & 1 & 1 & 2 \\
\hline Cartazes & 0 & 0 & 2 & 2 & 4 \\
\hline Jornais & 0 & 0 & 1 & 1 & 2 \\
\hline Folders & 0 & 0 & 1 & 1 & 2 \\
\hline $\begin{array}{l}\text { Propaganda } \\
\text { visual }\end{array}$ & 0 & 0 & 1 & 1 & 2 \\
\hline Telefone & 2 & 0 & 0 & 0 & 2 \\
\hline Não opinaram & 1 & 0 & 0 & 0 & 1 \\
\hline
\end{tabular}

Fonte: Elaborado pelas autoras

Percebe-se que nas quatro regiões do município, a comunicação boca a boca se sobressai sobre as outras formas de comunicação, estando em segundo lugar nesta pesquisa a emissora de rádio e posteriormente a mídia social.

A comunidade local também foi indagada sobre a importância de se ter um calendário de eventos no município. Apenas na campanha três entrevistados mencionaram que não acreditam haver necessidade; nas demais regiões houve aprovação de $100 \%$. Eles acrescentaram que é importante para poder se programar com antecedência e que é necessário divulgar a informação. Constata-se, pois, que é de suma importância a necessidade do calendário de eventos no município para a divulgação dos eventos, ter como referência, sendo uma consulta rápida e facilitadora.

É relevante enfatizar que a elaboração prudente e caracterizada de um calendário de eventos desenvolve o número de visitantes, indica oportunidades para atividades econômicas, promove a geração de emprego e renda, divulga diretamente um local ou região, minimiza a sazonalidade turística e amplia a arrecadamento de impostos (DENARDIN, 2013).

\section{Conclusão}

Este trabalho buscou verificar a importância de um calendário de eventos online para o município de Santa Vitória do Palmar potencializando sua divulgação a partir do marketing digital. Notou-se de que há dificuldade na divulgação dos eventos que se realiza no município, que dificulta a participação da população nos acontecimentos.

Analisando os resultados dos dados coletados, notou-se a necessidade da implantação de um calendário de eventos online, pois constatou-se que a comunidade seria mais participativa se tivesse melhor acesso à uma fonte de informação 
correta. Além disso, o calendário de eventos é uma fonte de consulta para formar uma imagem tanto do evento quanto da localidade, servindo para pesquisas posteriores.

O calendário de eventos deve englobar todos os eventos planejados para o ano corrente e seguintes em Santa Vitória do Palmar, sejam privados ou públicos, porém, no calendário de eventos da Prefeitura Municipal de Santa Vitória do Palmar não existe qualquer informação. Ao entrar no site, não se encontra o calendário, apenas uma publicação no Jornal Liberal, especificando uma lei de que foi aprovado o calendário de eventos no dia 18 de janeiro de 2016, e que esse documento é usado para fins orçamentários.

Ao finalizar o trabalho, conclui-se a grande necessidade de ter mais eventos no município, por ser um grande movimentador do fluxo de pessoas e também de recursos financeiros, em consequência disto nota-se a importância da implantação de um calendário de eventos no município de Santa Vitória do Palmar, pela necessidade da população manter-se atualizada e poder participar dos eventos sem dificuldade em conseguir a informação. 0 calendário ainda traz uma publicidade maior para aqueles que querem divulgar seus eventos, tornando-se uma grande ligação entre os promotores de eventos e os apreciadores.

Este estudo não se limita a este artigo, ele sugere a implantação de um calendário de eventos no site da prefeitura municipal, contendo todos os eventos locais (públicos ou privados), constando data de execução dos eventos, horários, valores de ingressos (se houver), programação, forma de adesão, mapa de localização, localidade, empresas organizadoras, patrocinadores, locais de hospedagem, restaurantes, um mapa da cidade incluindo as praias, telefones úteis, entre outros itens. Este site poderá contar com um espaço para reclamações, sugestões e elogios, bem como possibilidade de cadastro de telefones, onde os interessados receberão mensagens telefônicas com detalhes do evento, podendo estar atualizado mesmo sem ter acesso a internet, que é um problema que ocorre muito no interior do município. Além de estar disponível na internet, será impresso para àqueles que não tem contato com a tecnologia, como a campanha, por exemplo. Para conseguir divulgar um evento, a pessoa ou empresa entrará em contato com o administrador do site através do telefone ou e-mail.

Relatam-se também algumas dificuldades encontradas durante o processo de pesquisa e levantamento de informações, como a falta de interesse da Secretaria de Cultura (SECTUR) em disponibilizar o calendário de eventos municipal. Outra dificuldade foram as distâncias percorridas para a coleta de dados.

Este trabalho justifica-se por ser o pioneiro na cidade a levantar dados de quatro regiões distantes umas das outras, apesar de estar no mesmo município, abarcando as dificuldades e opiniões de diferentes públicos, constatando muitas vezes a heterogeneidade de respostas quando se compara uma região da outra.

Acredita-se que o município poderá beneficiar-se com os estudos que estão sendo realizados no campus da FURG, sendo este trabalho apenas um da primeira turma do Curso Superior de Tecnologia em Eventos que se encerrou em junho de 2016, formando profissionais qualificados para atuar no mercado de trabalho, assim, legitimando ainda mais a importância desta pesquisa e deste curso em Santa Vitória do Palmar. 


\section{REFERÊNCIAS}

ABEOC \& SEBRAE. (2013). II Dimensionamento Econômico da Indústria de Eventos no Brasil, 2013. São Paulo, SP: Revista dos Eventos.

AMPRO. (2015). Tendência Mobile 2015. Disponível em:< http://ampro.com.br/admin/ Files/PDF/AMPRO $\% 20$ no\%20Mobile $\% 20$ Intelligence $\% 20-\% 208 \%$ C2\%AA $\% 20$ edi $\%$ C3\%A7\%C3\%A3o.pdf >. Acesso em 28 de junho de 2016.

Britto; J., Fontes; N. (2002). Estratégias para eventos: uma ótica do marketing e do turismo. - São Paulo: Aleph.

Boaria, F. (2013). 0 e-commerce nos meios de hospedagem: Principais ferramentas utilizadas pelas redes hoteleiras no Brasil. 193 f. Dissertação (Curso de Mestrado em Turismo e Hotelaria), Universidade do Vale do Itajaí, Balneário Camboriú: Santa Catarina, 2013.

Boaria, F; dos Anjos, S. J. G.; Raye, R. L. (2014). Implementation of e-marketing in the Brazil hotel chains. Tourism \& Management Studies, v. 10, n. 2, p. 116-122.

Castelli, G. (2006). Gestão Hoteleira. - São Paulo: Saraiva.

Chleba, M. (1999). Marketing Digital: novas tecnologias e novos modelos. - São Paulo: Futura.

Crescitelli, E.; Shimp, T. A. (2012). Comunicação de marketing: integrando propaganda, promoção e outras formas de divulgação. - São Paulo: Cengage Learning.

Denardin, V. C. C. (2013). Turismo na Sociedade Midiatizada: o Calendário de Eventos como Ferramenta de Divulgação e Informação de Santa Maria, Rio Grande do Sul, Brasil.

Fotis. J.; Buhalis. D.; Rossides. N. (2012). Social Media Use and Impact during the Holiday Travel Planning Process. 2012. Disponível em: < https://www.researchgate.net/publication/270393508_Impact_of_Social_Networking_Sites_on_Hospitality_and_Tourism_Industries_Impact_of_Social_Networking_Sites_on_Hospitality_and_Tourism_Industries > Acesso em: 28 nov. 2016.

IBGE. (2015). Instituto Brasileiro de Geografia e Estatística. Disponível em: < http:// www.ibge.gov.br/home/estatistica/populacao/estimativa2015/estimativa_tcu.shtm. > Acesso em: 10 jun. 2016.

Iguassu Convention \& Visitors Bureau. Disponível em: $<$ http://iguassu.com.br/calendario-de-eventos/>. Acesso em 20 maio 2016.

Le Goff, J. (1982). História e memória. 70 ed. - Lisboa: Lugar da História,

Martin, V. (2007). Manual prático de eventos. São Paulo: Atlas.

Manap, K., Adzharud, N. (2013). The role of user generated contente (UGC) in social media for tourism sector, p. 52-58.

Torres, C. (2009). A bíblia do marketing digital: tudo o que você queria saber sobre marketing e publicidade na internet e não tinha a quem perguntar. São Paulo: Novatec. . (2010). Guia prático de marketing na internet para pequenas empresas. Copyright.

Zitta, C. (2013). Organização de Eventos: da ideia à realidade. 5.ed - Brasília: Editora Senac-DF. 


\section{Contribuição}

FrancIELI BoARIA: DEFINIÇÃo DO PROBLEMA DE PESQUiSA E OBJETIVOS; DESENVOLVIMENTO DA PROPOSIÇÃO TEÓRICA, REALIZAÇÃO DA REVISÃO BIBLIOGRÁFICA E FUNDAMENTAÇÃO TEÓRICA; ESCOLHA DOS PROCEDIMENTOS METODOLÓGICOS; ANÁLISE DE DADOS; ELABORAÇÃO DE TABELAS, GRÁFICOS E FIGURAS; REVISÃO CRÍTICA DO MANUSCRITO; REDAÇÃO DO MANUSCRITO; ADEQUAÇÃO DO MANUSCRITO ÀS NORMAS DA RTA.

Lidiane Caldeira de Souza: realização da revisão bibliográfica e fundamentação; coleta de dados; análise de dados; elaboração de tabelas, gráficos e figuras; redação do manuscrito. 